\title{
A escola na contemporaneidade: uma análise crítica do bullying
}

\author{
Fernanda Canavêz \\ Universidade Federal Rural do Rio de Janeiro (UFRRJ) - Seropédica - RJ
}

\section{Resumo}

Este artigo busca circunscrever a escola na contemporaneidade a partir de uma análise crítica do bullying. O objetivo é desdobrar esse fenômeno em quatro eixos principais, investigados por meio de uma revisão bibliográfica: a crise da autoridade docente, o discurso de vitimização, a judicialização da vida e o apelo aos especialistas, dentre os quais o profissional de Psicologia. Conclui-se que a escola constitui um espaçotempo que produz subjetividades e, como tal, apresenta poderes e resistências, em um movimento sempre pendular que ora adere aos discursos hegemônicos - como o que versa sobre bullying - ora é capaz de a estes resistir.

Palavras-chave: Escolas; contemporaneidade; bullying.

\section{School in contemporary: a critical analysis of bullying}

\begin{abstract}
This article searches to circumscribe the school in contemporary society from a critical analysis of bullying. The aim is to show this phenomenon into four main subject-matter, investigated through a literature review: the teaching authority crisis, the discourse of victimization, the use of laws to control the life and the appeal to experts, among them the professional psychology. It concludes that the school provides a kind of space and time that produces subjectivities and as such has powers and resistance, sometimes with a tendency toad here to the hegemonic discourses - as to what is about bullying - sometimes is able to resist these.
\end{abstract}

Keywords: Schools; contemporaneity; bullying.

\section{La escuela en la contemporaneidad: un análisis crítico del bullying}

\section{Resumen}

Este artículo busca circunscribir la escuela en la contemporaneidad a partir de un análisis crítico del bullying. El objetivo es desdoblar ese fenómeno en cuatro ejes principales, investigados por medio de una revisión bibliográfica: la crisis de la autoridad docente, el discurso de victimización, la judicialización de la vida y el llamado a los especialistas, entre los cuales el profesional de Psicología. Se concluye que la escuela constituye un espacio-tiempo que produce subjetividades $\mathrm{y}$, como tal, presenta poderes y resistencias, en un movimiento siempre pendular que ya adhiere a los discursos hegemónicos - como el que versa sobre bullying - ya es capaz de resistir a estos.

Palabras clave: escuelas; contemporaneidad; bullying. 


\section{Introdução}

Este artigo decorre da revisão bibliográfica levada a cabo no quadro da pesquisa intitulada Modos de subjetivação e contemporaneidade: o fenômeno do bullying a partir da narrativa de profissionais da Educação Básica. Parte-se da percepção de que o contexto escolar apresenta atualmente características afinadas ao que ora denominamos mal-estar na contemporaneidade, isto é, o mal-estar experimentado (e produzido) pelas chamadas formas de subjetivação contemporâneas, cenário em que o bullying desponta como um verdadeiro fenômeno de nossa época, marcado que é por descontinuidades em relação à modernidade que nos antecedeu.

Essas descontinuidades podem ser descritas segundo os eixos temáticos construídos após o estudo de teóricos que se propõem a tratar das transformações pelas quais nossa cultura estaria passando, a saber: a crise da autoridade docente (Aquino, 1998; Costa, 2005), o discurso de vitimização (Eliacheff, \& Larivière, 2007), a judicialização da vida (Bauman, 2005/2007) e o apelo aos especialistas (Giddens, 1990/1991). Esses temas foram privilegiados em detrimento de tantos outros por se supor que estejam diretamente relacionados às peculiaridades da escola na contemporaneidade, como será desenvolvido ao longo da argumentação. Objetiva-se, desta feita, investigar tais eixos no intuito de contribuir para uma perspectiva crítica sobre o fenômeno do bullying, subvertendo a concepção que o naturaliza, adotando-o como uma verdade descontextualizada e desprovida de determinantes histórico-políticos.

Cabe esclarecer que, para se chegar à afirmação de modos de subjetivação contemporâneos, destaca-se a premissa de que o processo de subjetivação é sobredeterminado, contemplando inúmeras forças que se entrelaçam em um permanente jogo de tensão entre o que seria da ordem do singular e do coletivo, do indivíduo e do social. De acordo com essa perspectiva, a subjetivação é engendrada em um contínuo processo de construção de si a colocar em xeque o estatuto ontológico do sujeito presente na tradição da Psicologia do século XIX e submetida à lógica cartesiana, qual seja, aquela referida a uma suposta essência, a categorias universais e a-históricas. Ao contrário dessa visada, a tensão acima aludida será profícua para a compreensão da subjetividade no presente artigo, marcada que é por um movimento pendular entre modelos construídos para conceituá-la, ainda que resguarde sempre a possibilidade de resistir a estes.

Essa leitura pode ser depreendida do pensamento foucaultiano sobre as formas de subjetivação (Potte-Bonneville, 2004), fazendo premente investigar os acontecimentos históricos, bem como as formas de poder e de resistência a eles atrelados (Foucault, 1984), quando se toma a subjetividade como objeto de estudo. Sendo assim, afirma-se a hipótese da passagem da modernidade à contemporaneidade, épocas que refletem expressivas modificações nas formas de subjetivação, mudanças que se fazem sensíveis em uma instituição como a escola, ela própria produtora de subjetividade.
Antes de prosseguir, cabe uma pequena digressão para esclarecer que a modernidade será entendida como o período caracterizado pelo projeto europeu para um ideal de civilização, de Estado, de família e, é claro, de sujeito. Projeto iniciado entre o Renascimento e o século XVII que ganha força na passagem deste para o século XVIII, com o declínio do poder soberano nos moldes da monarquia absolutista. As forças atuantes na consecução desse projeto teriam sido enfraquecidas e/ou transformadas no que se considera a inauguração do mundo contemporâneo que, para fins didáticos, será circunscrito ao período que sucede a Guerra Fria, no século XX, e perdura até os dias atuais, pelas modificações observadas no cenário social, dentre as quais o reordenamento da geopolítica e o desenvolvimento de tecnologias que alteraram sensivelmente as relações humanas, como a rede mundial de computadores.

É a partir desse contexto que se busca investigar os fenômenos considerados especialmente contemporâneos, como o bullying. Amplamente presente nas mais diferentes narrativas - das mídias de grande circulação, de mães e pais preocupados com o cuidado de seus filhos, do discurso jurídico que busca garantir/proteger os direitos de crianças e adolescentes e dos diversos segmentos do contexto escolar -, as falas sobre o bullying parecem constituir um emblemático representante da contemporaneidade na escola a aglutinar uma série de expectativas, propostas de intervenção e prevenção, valores e atitudes de enfrentamento e, por conseguinte, processos de subjetivação. Em última instância, trata-se de uma das versões do mal-estar contemporâneo que privilegia a escola como espaço-tempo para a sua expressão.

Cumpre salientar ainda o apelo popular em decorrência da produção desse fenômeno chamado bullying, tendência expressivamente fomentada, sobretudo no Rio de Janeiro, pelo tão comentado episódio ocorrido em uma escola de Realengo, bairro da zona norte da capital fluminense, em abril de 2011. Em uma manhã de quinta-feira, um ex-aluno retornou à unidade escolar onde cursara parte de seu processo de escolarização e abriu fogo, deixando alunos mortos e feridos. O ex-aluno teria sido "vítima de bullying", fato capaz de deixar as marcas indeléveis que o teriam impelido a ser o protagonista de tamanha tragédia, na expectativa da consecução de uma vingança a posteriori, uma das hipóteses veiculadas pela mídia, como tivemos oportunidade de comentar à época (Canavêz, \& Melgaço, 2011). Não seria exagero afirmar que o episódio mudou consideravelmente a cartografia dos conflitos nas escolas, uma vez que povoa o imaginário social e não cessa de ser mencionada, quase sempre em tom catastrófico e de uma tragédia anunciada passível de ser reproduzida a qualquer momento.

O cenário que faz recair sobre o bullying as inúmeras forças desencadeantes de um fato como o citado revela-se deveras reducionista. Todavia, o endereçamento feito aos especialistas capazes de "solucionar" seus pretensos aspectos desencadeantes e de trabalhar para a "prevenção" de situações disruptivas como esta tem sido a marca da demanda colocada ao profissional da Educação e, sobretudo, 
àquela endereçada à Psicologia. Com efeito, essa demanda também se faz notar em diversas esferas da sociedade que anseiam por uma reflexão (ou melhor, "solução") sobre os conflitos que atravessam o cotidiano escolar, tarefa à qual a Psicologia Escolar e Educacional é inequivocamente convocada sob a justificativa de que funcionariam como entraves ao processo ensino-aprendizagem. Apresentar-se-á o estudo dos eixos construídos para a análise do bullying com vistas a contribuir para a sua apreensão crítica e contextualizada, ultrapassando o reducionismo supracitado.

\section{O bullying na contemporaneidade: crise da autoridade docente e vitimização}

O surgimento do termo bullying pode ser identificado, segundo Dan Olweus (1993), já na década de 1960 - tendo ganhado mais relevância no decênio subsequente -, em pesquisas realizadas na Escandinávia. O termo era de uso frequente entre diferentes atores do contexto escolar, ainda que só tenha atraído a atenção da opinião pública quando as mídias de grande circulação começaram a abordar o assunto, atrelando os suicídios noticiados a agressões entre pares no ambiente escolar. Fato relevante foi o suicídio de três adolescentes, em 1982, precipitando uma campanha nacional que contou com o amplo apoio do governo norueguês (Olweus, \& Limber, 2010).

Mas, afinal de contas, o que é bullying? Não há uma resposta consensual para a pergunta, embora seja possível afirmar, de maneira geral, que se trata de uma relação de violência empreendida entre pares. É o que faz com que o termo não seja apenas referido ao contexto escolar, constatação possibilitada pelos inúmeros artigos produzidos que dele se utilizam para designar relações violentas entre colegas de trabalho, como exemplificam Fontes, Santana, Pelloso \& Carvalho (2013). Assim, pode-se observar que a circulação do termo extrapolou os limites da cultura norueguesa e se fez notar nas mais diversas partes do mundo, para designar circunstâncias igualmente diferentes.

De acordo com Antunes (2010), o termo passou a ser adotado em diversos países para se referir a situações que até então eram nomeadas com palavras de uso corrente nas diferentes culturas, com a proposta de facilitar sua classificação, reconhecimento, diagnóstico e prevenção. A autora apresenta um posicionamento crítico em relação a essa propagação (apoiada na Teoria Crítica da Sociedade da Escola de Frankfurt), problematizando se de fato esta contribui para a elucidação e esclarecimento a respeito da violência ou se estaria mais afeita à consolidação de uma determinada ideologia:

Os estudos com base apenas em dados estatísticos e no diagnóstico de sua ocorrência, assim como sua fácil assimilação e ampla divulgação pelos meios de comunicação de massa, o deslocamento causado por suas consequências e a inquestionável necessidade de intervenção via imperativos morais denunciam, ainda que apenas em lacunas, que tal conceito pode fazer parte de uma ciência instrumentalizada e a serviço da manutenção de uma ordem social desigual (Antunes, 2010, p. 39).

Nesse sentido, as citadas lacunas surgem até mesmo como importantes, na medida em que podem estar a serviço de escamotear sua filiação ideológica para exaltar um conceito, uma lógica e uma prática aparentemente neutros e a-históricos. A título de ilustração, vale comentar a suposição de intervenções calcadas em imperativos morais, uma das marcas incontestes do discurso que é tido como hegemônico no Brasil. É o que se pode observar a partir de alguns apontamentos de Cléo Fante (2005), um dos nomes comumente evocados em nosso país quando publicações a respeito do bullying estão em pauta, que identifica a ocorrência do fenômeno a partir de ausência de limites, da carência afetiva e da reprodução de maus tratos sofridos por crianças e adolescentes.

Chama a atenção o destaque conferido à falta de religiosidade como um dos possíveis determinantes do bullying, o que faz com que Fante (2005) sugira às famílias, como medida preventiva,

que se reúnam, ao menos uma vez por semana (com todos os meios de comunicação desligados), num clima de amor e paz, para discutir e refletir sobre os textos, parábolas ou histórias da bíblia, do evangelho ou de algum livro que ensine o valor da fé (p. 147).

É possível interpretar que a indicação traz, em um só tempo e proposta, pelo menos duas tendências: em primeiro lugar, a verificação do ponto de chegada de um processo iniciado na modernidade que encontra atualmente novos coloridos, qual seja, o enfraquecimento das formas de soberania e de autoridade tais como estavam estruturadas desde à época da monarquia absolutista. Em segundo lugar, a proposta de retomada de antigas práticas e discursos, em uma atitude que beira o saudosismo referente a um tempo supostamente melhor e perdido, para "solucionar" o que é tomado como impasse em nossa época.

Certos autores propõem (Costa, 2005; Giddens, 1990/1991), a partir do enfraquecimento acima aludido, a derrocada dos referenciais simbólicos que serviram de fundamento à subjetividade moderna, o que se dá a ver em duas esferas principais. Na perspectiva político-econômica, a soberania dos Estados-nação se mostra enfraquecida face à lógica neoliberal submetida à circulação do capital global, de modo que o Estado mínimo se apresenta como mais adequado ao neoliberalismo: regido pelo princípio da não-intervenção em prol da liberdade individual e da competição entre os agentes econômicos.

$\mathrm{Na}$ esfera micropolítica, a figura do pai, outrora detentora de plenos poderes em relação aos membros da constituição familiar, parece constituir o lugar privilegiado para o endereçamento de críticas e questionamentos por parte de grupos entendidos como minoritários, conforme exemplificam os movimentos gay e feminista que inicialmente toma- 
ram o patriarcado, circunscrito à função autoritária do pai, como alvo principal. Cumpre destacar também a figura do professor, marco importante na tarefa de imposição de limites e de contenção dos excessos da subjetividade moderna, funções que, pelos motivos acima mencionados, também sentem os efeitos das modificações anteriormente descritas. O quadro permite que se infira uma crise da autoridade docente (Aquino, 1998), exigindo que esse profissional se reinvente sob pena de se tornar "ultrapassado".

Este é o cenário contemporâneo em que o apontamento feito por Fante (2005) parece estar inserido, isto é, um contexto que não conta mais com os reguladores modernos do laço social, muito menos com os ideais de sujeito e de autoridade de outrora, concorrendo, entre outros aspectos, para a sensação de que o discurso religioso - um dos pontos de ancoragem simbólica - estaria enfraquecido ou, o que parece ainda mais pertinente, apresentar-se-ia em múltiplas versões, algo distintas do ideário religioso ao qual a civilização ocidental parecia acostumada. Em resposta a esse diagnóstico, entendido como problemático e passível de ser compreendido como um dos determinantes do bullying, Fante (2005) propõe a tentativa de retornar ao modelo de práticas religiosas que vigorara até então nas famílias brasileiras, na expectativa de que se possa resgatar o "clima de amor e paz" supostamente perdido. Trata-se de um posicionamento desprovido de crítica, pautado no discurso religioso via imperativos morais, a qual se entende ser imprescindível para analisar um fenômeno que faz parte da cultura que integramos (e construímos).

A propagação do termo bullying foi igualmente acompanhada do incremento do fenômeno, a ponto de ser designado como uma epidemia para a qual é preciso dar uma resposta contundente e efetiva (Palácios, \& Rego, 2006), enaltecendo a dimensão de produção de subjetividade que os discursos circulantes possuem. Diante da irrefutável ocorrência do que se convencionou chamar de bullying e do apelo endereçado, também à Psicologia, para que sejam tomadas medidas para combatê-lo, entende-se como premente a realização de estudos e proposições que possam analisá-lo criticamente.

Para isso é preciso partir de uma conceituação, mesmo que sua desconstrução se revele fértil e necessária ao longo do percurso de pesquisa, no intuito de elaborar um conceito que esteja mais afinado à realidade pesquisada. Desta feita, acompanhando Olweus (1993), parte-se da proposta de compreensão do bullying como a exposição de um aluno - entendido por este autor como vítima - de maneira repetitiva e durante um determinado tempo, a ações negativas empreendidas por parte de um ou mais colegas. Essas ações são caracterizadas por comportamentos agressivos que buscam causar desconforto na vítima, seja através de agressões físicas, verbais ou ainda gestos capazes de indicar o ato de exclusão da vítima de determinado grupo.

Essa definição restringe a ocorrência do bullying ao ambiente escolar e expõe o aluno como vítima de comportamentos de outrem, o que parece estar plenamente de acordo com mais uma das características que destacamos na contemporaneidade, qual seja, o incremento do discurso de vitimização, fazendo com que alguns a chamem de Era ou Tempo das Vítimas (Eliacheff, \& Larivière, 2007). De acordo com essa leitura, a figura da vítima assumiria o lugar antes destinado ao herói, ou seja, aquele que se destaca da massa homogênea de seus semelhantes, permitindo ao psiquiatra infantil Daniel Marcelli (2006) enaltecer o fomento atual da ocorrência do par indivíduo/reivindicação, o outro lado da perversa moeda que exalta o par indivíduo/performance.

Sendo assim, reivindicação e performance seriam duas importantes faces das formas de subjetivação contemporâneas, as quais lançariam mão da primeira na impossibilidade (absolutamente esperada, vale dizer) de atingir os níveis performáticos dos ideais contemporâneos de beleza, consumo e produção. Chega-se, desse modo, a mais um dos modos por meio dos quais podemos aventar a escola na contemporaneidade, marcada que é hoje pela exigência de cumprimento de metas e a exposição a níveis de competitividade que reproduzem a ideologia de uma sociedade cujo motor é o individualismo, associado à possibilidade de se destacar pela vitória sobre os demais.

Caso não atinja o esperado, o sujeito é imediatamente enviado ao signo do fracasso, expressão que se tornou um verdadeiro lugar-comum no sistema educacional, como analisa Cordié (1993/1996) ao lembrar que o fracasso se opõe ao sucesso, um dos valores de mais importância na sociedade ocidental:

Ser bem-sucedido na escola é ter a perspectiva do ter, mais tarde, uma bela situação, de ter acesso, portanto, ao consumo de bens. Significa também 'ser alguém', isto é, possuir o falo imaginário, ser considerado, respeitado. O dinheiro e o poder, não são eles a felicidade? O próprio Estado alimenta essa aspiração. Para ser grande, uma nação não deve sempre aumentar suas riquezas e suas competências? (p. 21).

$\mathrm{Na}$ realidade brasileira a situação não é diferente. Prova disto é a criação pelo Instituto Nacional de Estudos e Pesquisas Educacionais Anísio Teixeira (INEP), em 2007, do Índice de Desenvolvimento de Educação Básica (IDEB), que objetiva avaliar, em uma escala de zero a dez, a aprovação e a média de desempenho dos estudantes da educação básica em matemática e língua portuguesa ${ }^{1}$. A existência de medidas para avaliar a qualidade da educação não parece, em absoluto, passível de críticas, tendo em vista a importância da avaliação do processo ensino-aprendizagem até mesmo para aventar melhorias e transformações que estejam a serviço de um processo de escolarização efetivamente democrático. Todavia, o estabelecimento de metas e o modo como o processo se instaura na realidade de cada unidade escolar indica o caráter perverso destacado por Marcelli (2006).

Para exemplificar, vale mencionar que a prefeitura do Rio de Janeiro instituiu o Prêmio Anual de Desempenho, pago a todos os servidores das escolas que atingirem as

1 Para mais informações consultar <www.inep.gov.br>. 
metas previamente traçadas para cada unidade escolar. Conforme decreto de 16 de fevereiro de 2011 (Brasil, 2011), o prêmio é um salário extra, o chamado décimo quarto salário, condicionado às metas de acréscimo previstas em relação ao Ideb nos anos ímpares e às metas de acréscimo previstas no tocante ao Índice de Desenvolvimento da Educação do Rio de Janeiro (IDE-Rio) nos anos pares. Cabe ainda mencionar o elevado nível de insatisfação dos docentes deste município com as condições salariais, uma realidade histórica em nosso país, muito embora reflita expressiva força devido ao movimento de greve iniciado em agosto de 2013, que contou com a ampla adesão de profissionais da Educação do estado e do município.

Desse modo, a oferta da possibilidade de mais um salário anual impele muitos profissionais a empreenderem todos os esforços para recebê-lo, assolados por lastimáveis condições de trabalho: ausência de plano de cargos e salários, reajustes salariais que não acompanham nem mesmo o índice da inflação e a diminuição progressiva dos espaços coletivos de discussão em favor de um suposto aumento de produtividade. Com isso, os índices, ao invés de contribuírem para uma análise consistente e produtiva para repensar o sistema educacional, acabam acirrando as diferenças entre "bons" e "maus" alunos ("bons" e "maus" professores), sem o aprofundamento de quaisquer reflexões sobre os determinantes dessa realidade. Ademais, aumentam exigências descontextualizadas que reduzem os históricos dos alunos e de suas famílias, de sua relação com a escola e desta com a comunidade em que se insere em números absolutos e, não poucas vezes, excludentes.

O enfraquecimento dos referenciais que serviam de balizadores para a subjetividade moderna, entre eles a figura do professor, e a difusão da cultura da vitimização alicerçam as bases não só para o surgimento do fenômeno do bullying, mas também para a sua propagação e para as proposições de enfrentamento deste na contemporaneidade. A produção desse fenômeno eminentemente contemporâneo traz inúmeros desafios para a escola e, por conseguinte, para a Psicologia Escolar e Educacional, marcada que está pelo interesse por aspectos que se interpõem ao processo de ensino-aprendizagem.

\section{A escola na contemporaneidade: judicialização e apelo ao especialista}

O mandato de ter que lidar com os mais variados conflitos precipitados nas relações de ensino-aprendizagem é mais um dentre tantos outros que são reservados à escola hoje. Uma das formas por meio das quais se entende dar uma resposta à problemática é o estabelecimento de parâmetros jurídicos dos quais se espera conter, impor limites ao que estaria entravando o processo ensino-aprendizagem, regulando/regulamentando os comportamentos tomados como excessivos. Essa tendência pode ser lida sob a ótica da judicialização da vida, isto é, movimento de ampla convocação do judiciário para intervir nas relações humanas, uma das faces assumidas pela forma de governo da modernidade (Foucault, 1978/2004), a partir da qual se podem identificar linhas de continuidade na contemporaneidade. Apresenta-se, assim, uma das tentativas para resgatar a autoridade perdida, ao lado da proposta de retomada da moral religiosa. Essa expectativa se faz notar em diversos projetos de lei e legislações antibullying, presente em diversos estados e municípios brasileiros.

No Estado do Rio de Janeiro, por exemplo, há pelo menos duas leis sancionadas pelo atual governador: a que dispõe sobre medidas para o combate ao bullying, obrigando escolas a notificarem ao Conselho Tutelar e à polícia os casos de bullying e de violência contra crianças e adolescentes (Lei n. 5824, 2010) e a que institui a primeira semana de abril como de combate ao bullying e ao cyberbullying (Lei n. 6.401, 2013), data escolhida em homenagem às crianças atingidas pelo ocorrido em Realengo, no mês de abril de 2011. Na perspectiva da sugestão dada por Fante, novamente desponta um posicionamento desprovido da crítica à qual se chegaria se os inúmeros fatores concorrentes para a precipitação de um fenômeno como o bullying fossem considerados. Como fenômeno sobredeterminado e, como tal, multifacetado, mostra-se recalcitrante aos imperativos morais, através dos quais não raras vezes busca-se racionalizar e organizar a realidade dos conflitos.

Como um dos resultados dos imperativos colocados pela sociedade (até mesmo sob a forma de legislações), vale lançar luz sobre o apelo aos especialistas, presente em todo o tecido social e, arrisca-se afirmar, de modo ainda mais marcante nas escolas, devido à articulação entre a crise da autoridade - também a docente - e o incremento do apelo ao cientificismo que acaba concorrendo para a desqualificação dos saberes construídos pelos profissionais da Educação. Aqui se nota igualmente o ponto de chegada de um processo iniciado na modernidade, como sustenta Guarido (2011) ao afirmar que o avanço do cientificismo nesse período veio acompanhado da validação de uma nova autoridade, especialista na educação das crianças, qual seja, o discurso médico-psicológico. Este é convocado tanto nas suspeitas de diagnósticos quanto na demanda para que estes sejam realizados.

No que diz respeito ao fenômeno do bullying e toda sorte de conflitos encontrados no ambiente escolar a situação não parece ser diferente, de modo que se observa um endereçamento à Psicologia geralmente fomentado pela difusão do modelo clínico tradicional de atuação, expresso no pedido de tratamento de alunos e/ou acompanhamento de suas famílias nos moldes ambulatoriais, na expectativa de reparar algo - seja de sua constituição psíquica ou das famílias entendidas como desestruturadas - que os tornaria afeitos à prática do bullying. É o que pudemos observar na intervenção em grupos focais junto a representantes de escolas da cidade do Rio de Janeiro, de diversos segmentos, interessados em estratégias para lidar com os conflitos na escola (Canavêz, \& Oliveira, 2013).

A leitura de Giddens (1991) fornece elementos que auxiliam a compreender o movimento de apelo aos especia- 
listas a partir do que o autor chama de sistemas peritos, um mecanismo de desencaixe dos sistemas sociais, isto é, do deslocamento das relações sociais de contextos locais de interação, tais como eram observadas nas sociedades tradicionais marcadas pelo tête-à-tête. Na atualidade, ao contrário, saberes especializados são continuamente consultados e, muito embora não estejamos inteiramente a par de como funcionam seus conhecimentos, neles depositamos nossa confiança e os norteadores para a racionalização do ambiente (social e material) em que vivemos. Desse modo, demanda-se de especialistas a resolução de conflitos, dentre os quais cabe incluir o bullying, ainda que esses profissionais não estejam inseridos na escola, apresentando-se, portanto, desencaixados do contexto em que surge a demanda.

São criadas assim as condições para que a escola seja tomada como palco de experimentos e oferta de projetos - que partem da premissa "de que os professores nada sabem, ou que o que sabem não tem muito valor, já foi superado" (Rego, 1998, p. 52) -, com intervenções frequentemente pontuais e que não deixam seu legado para a unidade escolar, o que exigiria que seus atores fossem envolvidos não só na idealização, como na execução e na avaliação de todas as iniciativas. É preciso, dessa forma, também potencializar as iniciativas já empregadas pelas próprias escolas, ainda que nem sempre sejam encaradas como tais, invadida que esta instituição está pelo discurso de apelo aos especialismos, enxergando-se, ela própria, como desqualificada e incapaz para lidar com o que se interpõe em seu cotidiano.

É importante esclarecer que por potencialização das iniciativas empregadas pela escola não se entende a atribuição de um juízo de valor "positivo", o que extrapola os limites deste artigo. Ao contrário, busca-se implicar a escola como uma das forças concorrentes para a produção dos mais variados fenômenos que a atravessam, tanto do que pode ser interpretado como "fracasso" quanto "sucesso", etapa fundamental para que essa instituição possa se (re)apropriar de seu lugar/função no processo ensino-aprendizagem. Desse modo, trata-se muito mais de compreender a escola como positividade (Ezpeleta, 1986), ou seja, como instituição que pode tecer sua rede de serviços no território de que faz parte, construir uma linguagem e métodos próprios para lidar com suas questões, apresentar, enfim, modos singulares de lidar com o universal das políticas públicas.

\section{Poderes e resistências na escola}

Para avançar nessa discussão, propõe-se uma leitura que supõe um diálogo entre Michel de Certeau e Michel Foucault, muito mais do que a ênfase da crítica do primeiro ao segundo, para desinvisibilizar o manejo da escola em relação ao que se convencionou chamar de bullying. Em primeiro lugar, o pensamento de Certeau apresenta sua relevância por uma questão político-conceitual. Isto porque tem sido amplamente evocado no campo da Educação pelas chamadas pesquisas nos/dos/com os cotidianos (Alves, 2010), isto é, por pesquisadores que buscam superar a ideia de que se voltar para os cotidianos, com suas narrativas e práticas, seria desconsiderar a teoria. Ao contrário, a ênfase nas práticas pedagógicas cotidianas e nas narrativas dos praticantes pretende enaltecer justamente suas técnicas e ideias face à tendência dos discursos hegemônicos (Certeau, 1980/1994). Desse modo, os professores, por exemplo, não devem ser tomados como meros objetos de observação e fontes de recursos metodológicos, mas adquirem o estatuto de "personagens conceituais" (Alves, 2010, p.1203), cujas narrativas e imagens alimentam e (re)inventam as pesquisas.

Certeau (1980/1994) analisa o comportamento estratégico, por parte das instituições, que busca sistematizar e impor uma determinada ordem, e o tático, por parte de pessoas ditas comuns, que emerge de uma necessidade colocada no cotidiano e se infiltra pelas malhas do que está colocado no nível estratégico. O objetivo não é chegar à dominação, conforme pressuposto em táticas de guerrilha, mas lançar mão da flexibilidade para escapar às ordens e discursos hegemônicos: trata-se do comportamento dos praticantes, de personagens conceituais que transitam no (constituem o) ambiente da escola evidenciando suas táticas para lidar com o que o comportamento estratégico convencionou chamar de bullying e, em última instância, com os imperativos de judicialização e apelo aos especialistas.

O autor em questão critica uma determinada acepção do poder em Foucault, por reconhecer nesta o privilégio concedido aos aparelhos produtores do poder disciplinar ${ }^{2}$, na medida em que ao entender o poder pulverizado nas malhas do social (e não como posse de uns contra outros que não o deteriam, conforme a perspectiva jurídica de poder), Foucault teria deixado escapar justamente que "procedimentos populares (também minúsculos e cotidianos) jogam com os mecanismos da disciplina e não se conformam com ela a não ser para alterá-los" (Certeau, 1980/1994, p. 41).

A afirmação busca tornar visíveis as táticas que teriam permanecido enfraquecidas no discurso foucaultiano. Entretanto, entende-se que as formulações mais tardias de Foucault, na fase de suas formulações denominadas estética da existência, em que a ênfase recai na pesquisa das formas de subjetivação (Foucault, 1982/1994), também apresentam um fundamento conceitual consistente e operacional para investigar sejam as táticas - como se encontra em Certeau -, sejam as formas de resistência - como descritas por Foucault.

Foucault (1976/2009) não só reafirma a problematização da concepção jurídica e economicista de poder presente na sua genealogia do poder - como se o poder fosse algo que se poderia deter - para afirmá-lo capilarizado nas malhas do social, nas mais diversas relações, instituições e discursos; mas também faz questão de ressaltar que "onde há poder há resistência" (p. 105), de modo que

2 Segundo Foucault (1976/2009), o poder disciplinar ganha forma na passagem do século XVII para o século XVIII a partir da perda de ênfase atribuída ao poder soberano. Trata-se de um tipo de poder exercido por meio de dispositivos disciplinares - como aquele da sexualidade -, que visam a docilização dos corpos. Pelo fato de não contar com um centro executor, como o poder soberano na perspectiva jurídica, o poder disciplinar é exercido de modo invisível, dificultando que se Ihe oponha. 
não há uma exterioridade da última em relação ao primeiro. Aliás, as formas de resistência importam justamente porque constituem uma espécie de "catalisador químico" (Foucault, 1984 , p. 300 - tradução nossa), capazes de desinvisibilizar as relações de poder quase nunca evidentes. Nesse sentido, há três tipos de lutas - tomadas no arcabouço teórico foucaultiano de modo sinonímico em relação às resistências conforme os tipos de poder a que se encontram associadas: as que se opõem às formas de dominação (étnicas, sociais e religiosas), as que denunciam as formas de exploração que separam o indivíduo de sua produção e, por fim, as que combatem tudo que liga o indivíduo a ele mesmo: as formas de assujeitamento, em outros termos, de submissão às formas de subjetividade, por exemplo, do tipo de individualização favorecido pelas forças contemporâneas.

Esse referencial permite ampliar a ideia de que seria preciso combater a opressão empreendida pelo Estado, pelos imperativos de vitimização e de judicialização preconizados por outrem, para compreender que o sujeito, ele próprio, é constituído (e se constitui) nesse campo de forças e, dessa maneira, também se insere na esteira desses apelos. Esse pressuposto foucaultiano permite inferir que não há professores "bons" ou "maus", alunos "fracassados" ou "bem-sucedidos", mas formas de subjetivação que se apresentam em movimentos pendulares que ora se aproximam da submissão a determinados tipos de subjetividade valorizados pelos imperativos contemporâneos, ora resistem a estes, independente do modo como essa resistência se dá.

Assim, seria até mesmo cabível questionar em que medida o bullying e outras formas de conflito na escola não seriam formas de resistir ao sistema educacional proposto e, em última instância, ao modelo de subjetividade esperado/ imposto no contexto escolar. Este parece responder à expectativa de um aluno capaz de atingir o que se supõe ser uma boa performance, afinada a partir dos interesses do mercado, e valorizado por sua capacidade de competir. O bullying, de acordo com esse referencial, reflete os efeitos da propagação de um discurso que preconiza o rechaço dos considerados mais fracos e inaptos a corresponder um ideal de sucesso.

$\mathrm{Na}$ esteira desta proposta, é possível desconstruir a suposição de o que bullying seria uma epidemia fruto da falta de religiosidade ou de limites, passível de solução via imperativos morais. De maneira análoga, opera-se a desconstrução do bullying como um conceito naturalizado, utilizado para descrever/racionalizar fenômenos (Antunes, 2010), e como tal imune a críticas que busquem contextualizá-lo no quadro das transformações observadas nos chamados modos de subjetivação contemporâneos.

É a partir desse olhar que buscamos considerar a escola na contemporaneidade: constituída por sujeitos que sentem os efeitos e constroem a cultura de que fazem parte, entre poderes e resistências, mas sempre com a possibilidade de indagar o seu próprio tempo. Segundo Agamben (2006/2009), a contemporaneidade não seria apenas um período datado cronologicamente, mas um modo de relação com o tempo de que se faz parte, pois o contemporâneo "percebe o escuro do seu tempo como algo que lhe concerne e não cessa de interpelá-lo, algo que, mais do que toda luz, dirige-se direta e singularmente a ele" (p. 64).

É preciso, portanto, compreender as inúmeras forças que concorrem para a produção do que se denomina bullying, capaz de articular os mais diversos fenômenos que tomamos como especialmente contemporâneos nos limites deste artigo: a crise da autoridade docente, o discurso que enaltece o lugar de vítima, o apelo ao discurso jurídico e, por fim, a convocação do especialista, chamado a solucionar as questões das mais diferentes ordens. Cumpre não esquecer que essas questões são absolutamente esperadas em um contexto plural e democrático como deve ser a escola, portanto afeito às diferenças que o compõem, quase sempre manifestas em conflitos.

Estes foram os pontos destacados a partir da revisão bibliográfica que deu ensejo aos eixos temáticos utilizados com vistas a descontruir o conceito descontextualizado de bullying, primando por sua análise crítica. Espera-se passar agora à fase de realização, transcrição e análise de entrevistas semidiretivas com profissionais da Educação Básica na expectativa de investigar se as narrativas de tais personagens conceituais está em continuidade ou não com os aspectos destacados na pesquisa bibliográfica.

\section{Referências}

Agamben, G. (2009). O que é o contemporâneo?. Em G. Agamben. O que é o contemporâneo? e outros ensaios (V. N. Honesko, Trad., pp. 55-73). Chapecó: Argos. (Trabalho original publicado em 2006).

Alves, N. (2010). A compreensão de políticas nas pesquisas com os cotidianos: para além dos processos de regulação. Educação e sociedade, 31(113), 1195-1212.

Antunes, D. C. (2010). Bullying: razão instrumental e preconceito. São Paulo: Casa do Psicólogo.

Aquino, J. G. (1998). A violência escolar e a crise da autoridade docente. Caderno CEDES, 19(47), 7-19.

Bauman, Z. (2007). Vida líquida (C.A. Medeiros, Trad.). Rio de Janeiro: Jorge Zahar. (Trabalho original publicado em 2005).

Brasil. Decreto 33399, de 17 de fevereiro de 2011 (2011). Dispõe sobre os critérios de premiação a ser concedida aos servidores na forma que menciona. Atos do prefeito. Rio de Janeiro: Diário Oficial.

Canavêz, F., \& Melgaço, L. (2011). Tiros em Realengo. Correio Popular de Campinas.

Canavêz, F., \& Oliveira, V. (2013). Conflitos na Escola: contribuições da Psicologia para o campo da Educação. Trabalho apresentado na VII Mostra Regional de Práticas em Psicologia, Rio de Janeiro - RJ. 
Certeau, M. (1994). A invenção do cotidiano - artes de fazer (E.F. Alves, Trad.). Petrópolis: Vozes. (Trabalho original publicado em 1980).

Cordié, A. (1996). Os atrasados não existem: psicanálise de crianças com fracasso escolar (S. Flach, \& M. D'Argod, Trad.). Porto Alegre: Artmed. (Trabalho original publicado em 1993).

Costa, J. F. (2005). O vestígio e a aura: corpo e consumismo na moral do espetáculo. Rio de Janeiro: Garamond.

Eliacheff, C., \& Larivière, D. S. (2007). Le temps des victimes. Paris: Albin Michel.

Ezpeleta, J. (1986). La escuela y los maestros: entre el supuesto y la deducción. Em Centro de Investigación y de Estudios Avanzados del Instituto Politécnico Nacional (Org.), Edição 20 de Cuadernos de investigación educativa (pp. 55-70). Chile: CINVESTAV.

Fante, C. (2005). Fenômeno bullying: como prevenir a violência nas escolas e educar para a paz. Campinas: Versus.

Fontes, K., Santana, R., Pelloso, R., \& Carvalho, M. (2013). Fatores associados ao assédio moral no ambiente laboral do enfermeiro. Revista Latino-Americana de Enfermagem, 21 (3), 758-764.

Foucault, M. (2009). História da sexualidade I: A vontade de saber (M.T.C. Albuquerque, \& J.A.G. Albuquerque, Trad.). Rio de Janeiro: Graal. (Trabalho original publicado em 1976).

(2004). Securité, territoire, population: cours au Collège de France (1977-1978). Paris: Hautes Études/Gallimard-Seuil. (Trabalho original publicado em 1978).

(1994). Les technologies de soi-même. Em Dits et écrits IV (pp. 783-813). Paris: Gallimard. (Trabalho original publicado em 1982).

(1984). Deux essais sur le sujet et le pouvoir. Em H. Dreyfus, \& P. Rabinow (Orgs.), Michel Foucault: un parcours philosophique (pp. 297-321). Paris: Gallimard.
Giddens, A. (1991). As consequências da modernidade (R. Fiker, Trad.). São Paulo: UNESP. (Trabalho original publicado em 1990).

Guarido, R. (2011). A biologização da vida e algumas implicações no discurso médico sobre educação. Em CRP-SP \& Grupo Interinstitucional de Queixa Escolar (Orgs.), Medicalização de crianças e adolescentes: conflitos silenciados pela redução de questões sociais a doenças de indivíduos (pp. 30-46). São Paulo: Casa do Psicólogo.

Lei n. 5824, de 20 setembro de 2010 (2010). Altera o artigo $1^{\circ}$ da lei n. 4725 , de 15 de março de 2006 , e dá outras providências. Rio de Janeiro-RJ.

Lei n. 6401, de 05 de março de 2013 (2013). Institui a "Semana de combate ao bullying e ao cyberbullying" nas escolas públicas da rede estadual do rio de janeiro, altera a lei estadual $n^{\circ} 5.645$, de 6 de janeiro de 2010, e dá outras providências. Rio de Janeiro-RJ.

Marcelli, D. (2006). Les yeux dans les yeux. Paris: Albin Michel.

Olweus, D. (1993). Bullying at school: What we know and what we can do. Cambridge: Blackwell.

Olweus, D., \& Limber, S.P. (2010). The Olweus Bullying Prevention Program: implementation and evaluation over two decades. Em S. Jimerson; S. Swearer, \& D. Espelage (Orgs.). Handbook of bullying in schools: an international perspective (pp. 377-402). New York: Routlegde.

Palácios, M., \& Rego, S. (2006). Bullying: mais uma epidemia invisível?. Revista Brasileira de Educação Médica, 30(1), 3-5.

Potte-Bonneville, M. (2004). Michel Foucault, l'inquiétude de l'histoire. Paris: PUF.

Rego, T.C.R. (1998). Educação, cultura e desenvolvimento: o que pensam os professores sobre as diferenças individuais. Em J. G. Aquino (Org.), Diferenças e preconceitos na escola: alternativas teóricas e práticas (pp. 49-71). São Paulo: Summus.

Recebido em: 31/10/2013

Reformulado em: 10/05/2014

Aprovado em: 20/07/2015

\section{Sobre a autora}

Fernanda Canavêz (fernandacanavez@gmail.com)

Psicóloga, Professora adjunta do Departamento de Psicologia (DEPSI/UFRRJ) e do Programa de Pós-Graduação em Psicologia da Universidade Federal Rural do Rio de Janeiro (PPGPSI/UFRRJ); Doutora pelo Programa de Pós-Graduação em Teoria Psicanalítica (UFRJ).

Trata-se de artigo derivado de pesquisa contemplada com auxílio financeiro da Fundação Carlos Chagas Filho de Amparo à Pesquisa do Estado do Rio de Janeiro (FAPERJ). 